\title{
Identification of Up-Regulated Low Molecular Weight Proteins in Human Adipocytes Treated with Glycoxidized Albumin
}

\author{
Nihar Ranjan Singh, Philippe Rondeau and Emmanuel Bourdon* \\ Laboratoire de Biochimie et Génétique Moléculaire (LBGM), Groupe d'Etude sur l'Inflammation Chronique et l'Obésité \\ (GEICO), Université de La Réunion, Saint Denis de La Réunion, France
}

\begin{abstract}
Diabetes and Obesity are strongly associated with enhanced circulating advanced glycoxidation end products (AGEs), and adipose tissue constitutes a biological driver in the metabolic syndrome characterized by abdominal obesity, dyslipidemia and insulin resistance. We determined whether AGEs issued from glycoxidized albumin could induce expression of determinant proteins in human adipocyte cell lines (SW872).

Cell proteins separation by 2D gels and mass spectrometry were combined to identify up-regulated proteins in SW872 treated with AGEs. Four low molecular weight proteins appeared as more expressed in adipocytes treated with glycated albumin than with native albumin. All four proteins have determinant role in adipocyte physiology as they exert antioxidant activities (superoxide dismutase and proteasome subunit) or energy production properties (phosphoglycerate mutase and triosephosphate isomerase).

Proteomic analyses of SW872 cells have never been performed before. By using proteomic analyses, our results bring new evidence of AGEs-involvement in metabolic disorders at the adipocyte level.
\end{abstract}

Keywords: Glycoxidation, albumin, adipocytes, oxidative stress, SW872, glycation, diabetes.

\section{INTRODUCTION}

It is now well established that free radicals and reactive oxygen species (ROS) contribute to the development of several age-related diseases by inducing oxidative stress and oxidative damages [1]. The incidence of diabetes is increasing, with a worldwide prevalence estimated to double by 2030, primarily because of sedentary lifestyle and obesity [2]. A strong link between obesity and diabetes is now well established with more than 70 percent of people with diabetes being overweight. This disease, which is characterized by hyperglycemia and insulin resistance, is closely associated with severe complications. Indeed, diabetes increases the risk of developing cardiovascular disease, which represents the leading cause of mortality in western countries [3]. Recently, a causal role was shown for ROS in multiple forms of insulin resistance, which was also associated with elevated formation of advanced glycation end products (AGEs) [4]. Adipocytes are known to express and secrete a variety of active molecules, so-called adipokines, which can regulate many biological processes such as insulin-sensitivity, appetite, immunity, reproduction. It is now well established that dysregulation of adipocyte functions by oxidative stress constitutes a key process leading to type 2 diabetes. It is thus not surprising that many diabetic therapies target adipose tissue (thiazolidinedione, physical activity, etc) [5,6]. SW872 cells constitute a liposarcoma cell line often used as a human adipocyte cell model [7-12]. Nonetheless, proteomic analyses of SW872 cells have never been performed before. In

*Address correspondence to this author at the LBGM - Université de la Réunion - 15, avenue René Cassin - BP 7151 - Cedex 09, 97715 Saint Denis de La Réunion, France; Tel: (+262) 2629386 48; Fax: (+262) 26293 82 37; E-mail: emmanuel.bourdon@univ-reunion.fr this work, we determined whether AGEs issued from glycoxidized albumin could induce expression of determinant proteins in human adipocyte cell lines (SW872).

\section{MATERIALS AND METHODS}

\section{In Vitro Glycoxidation of BSA}

Non defatted recombinant BSA (Sigma, cat \# A2153) was dissolved in phosphate-buffered saline (PBS), $\mathrm{pH} 7.4$, to yield a stock solution of $50 \mathrm{mg} \cdot \mathrm{mL}^{-1}$. This solution was prepared with $200 \mathrm{mM}$ glucose solution in PBS, to form incubation mixtures of $50 \mathrm{mg} \cdot \mathrm{mL}^{-1}$ BSA with 0 or $100 \mathrm{mM}$ glucose. After being sterilized by filtration through $0.2 \mu \mathrm{m}$ filters (Millipore), the solutions were incubated at $37^{\circ} \mathrm{C}$ for 50 days in capped vials. Reversible and unbound glucose were removed from BSA by extensive dialysis against PBS, $\mathrm{pH}$ 7.4. Albumin preparations were assessed for glucose content after dialyses and the later was below detectable levels. Samples were separated into aliquots and stored at $80{ }^{\circ} \mathrm{C}$ in the dark prior to incubation with the SW872 cells. Endotoxin content was below detectable level (0.03 Endotoxate Unit $/ \mathrm{mL}$ ) as assessed with an in vitro toxicology assay kit (E-TOXATE, Sigma).

\section{Mass Spectrometry Studies of Native and Glycoxidized BSA}

Native BSA and glycoxidized BSA treated in the absence or the presence of $100 \mathrm{mM}$ of glucose, were analyzed using mass spectrometry for molecular weight and extent of glycoxidation determinations. ESI/MS was performed on Agilent 1100LC coupled to Bruker Esquire 3000plus operating in the positive ion mode as mentioned earlier [20]. 


\section{Cell Culture}

Human SW872 liposarcoma cells were purchased from American Type Culture Collection. Cells were seeded in sixmultiwell plates and grown in Dulbecco's modified Eagle medium (DMEM) containing 1.25\% L-glutamine, 2\% penicillin/streptomycin, and $10 \%$ fetal calf serum, in a humidified incubator $\left(5 \% \mathrm{CO}_{2}, 37^{\circ} \mathrm{C}\right)$. The culture plates were incubated until cells reach $75 \%$ confluency before adding $\mathrm{BSA}_{\mathrm{G} 0}$ or $\mathrm{BSA}_{\mathrm{G} 100}$ at a final concentration of $20 \mu \mathrm{M}$. Thereafter, cells were maintained in the humidified $\mathrm{CO}_{2}$ incubator for $16 \mathrm{~h}$ before further analyses.

\section{Cell Lysate Preparation}

After the incubation, the cells were washed twice with PBS. Then, cells were treated at $4^{\circ} \mathrm{C}$ during 30 min with 100 $\mu \mathrm{L}$ of lysis buffer containing $25 \mathrm{mM}$ Tris-HCl, $\mathrm{pH} 8.3,10$ mM KCl, 1 mM DTT, 1 mM EDTA, 1\% Triton X100. Cell lysates were then centrifuged at $15,000 \mathrm{rpm}$ at $4{ }^{\circ} \mathrm{C}$ for 20 min and the protein concentration were measured in the supernatant.

\section{Two-Dimensional Gel Electrophoresis}

The first dimension was performed utilizing Immobiline Drystrips ( $\mathrm{pH} \quad 6.2-7.5$, length $7 \mathrm{~cm}$ ) and the Multiphor II isoelectric focusing system (Amersham Pharmacia Biotech). $0.5 \mathrm{mg}$ protein from cell lysates was diluted in sample buffer (9 $\mathrm{M}$ urea, 2\% Chaps, 2\% Pharmalytes, $20 \mathrm{mM}$ dithiothreitol, and bromophenol blue). Lysates from SW872 cells treated with native and glycated albumin were isolated and separated on Immobiline Drystrips. The Drystrip was rehydrated in this solution in a re-swelling tray (GE Healthcare) overnight at room temperature and then focused for 50,000 $\mathrm{Vxh}^{-1}(23 \mathrm{~h})$. After focusing, the Immobilines Drystrips were equilibrated for $10 \mathrm{~min}$ in equilibration buffer $(50 \mathrm{mM}$ Tris$\mathrm{HCl}, \mathrm{pH}$ 6.8, $6 \mathrm{M}$ urea, 30\% (v/v) glycerol, 1\% w/v SDS) supplemented with $1 \%(\mathrm{w} / \mathrm{v})$ dithiothreitol followed by 10 min in equilibration buffer containing $2.5 \%(\mathrm{w} / \mathrm{v})$ iodoacetamide. The second dimension, SDS-PAGE, was performed using a $12 \%(\mathrm{w} / \mathrm{v})$ gel and the Protean II electrophoresis system (Bio-Rad). For each 2D experiment, two strips of 7 $\mathrm{cm}$ each were run side by side on the same gel. This experiment was replicated four times for consistency in
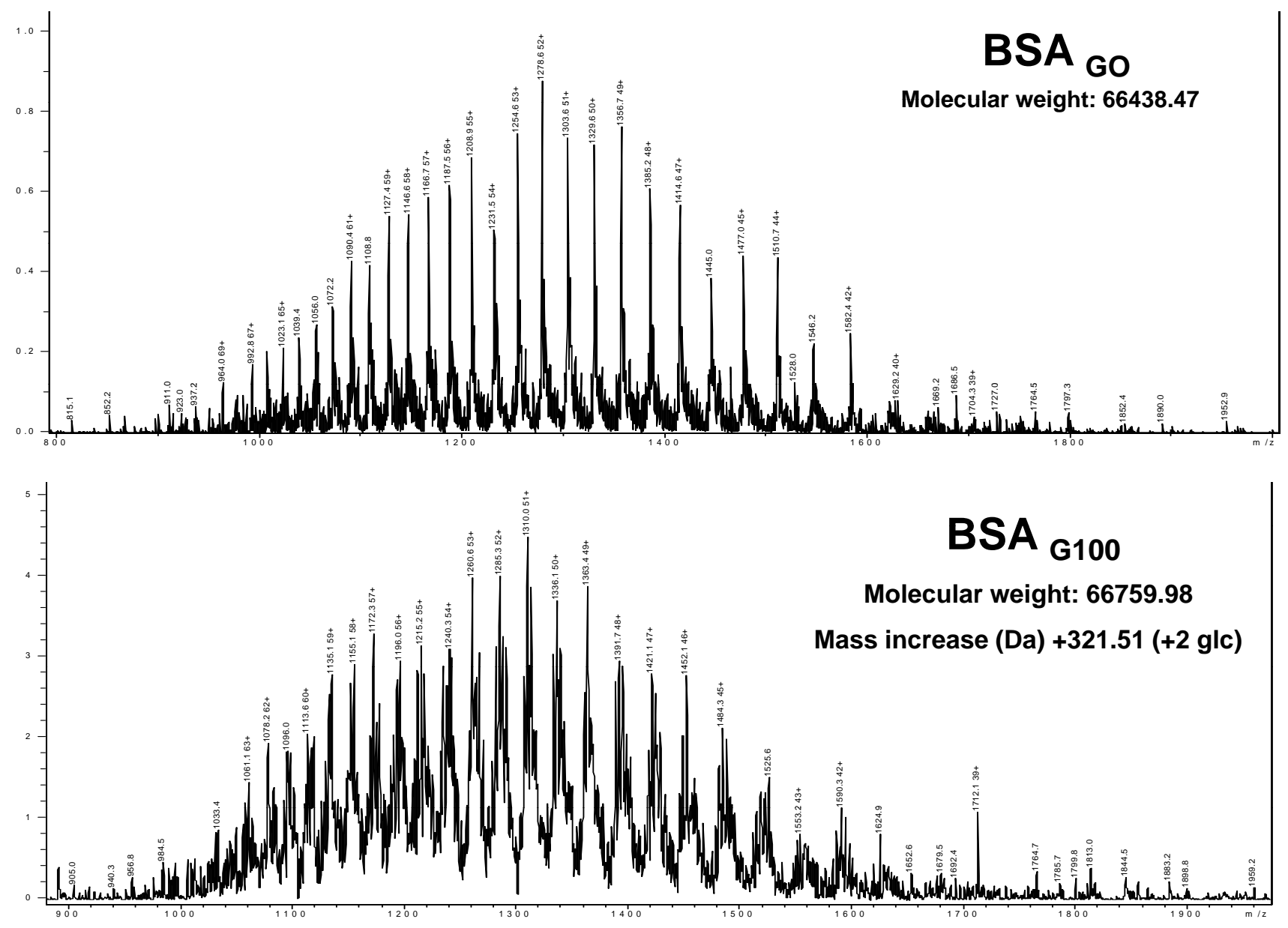

Fig. (1). Mass spectrometry analysis of native and glycoxidized BSA.

Native BSA and glycoxidized BSA treated in the absence or the presence of $100 \mathrm{mM}$ of glucose, were analyzed using mass spectrometry for molecular weight and extent of glycoxidation determinations. ESI/MS was performed on Agilent 1100LC coupled to Bruker Esquire 3000 plus operating in the positive ion mode as mentioned in [20]. 
results. These $2 \mathrm{D}$ gels were stained with silver nitrate following established protocols [13].

\section{Identification of Proteins}

Images generated from silver stained gels were compared. Co-localizing spots were excised from the silver stained gels and submitted separately for identification. Spots were sent for peptide mass fingerprinting identification by MALDI-TOF/TOF mass spectrometry, at the Plateforme Technologique de Biotechnologie Moléculaire (Université d'Angers, France). Signal quantifications from images were determined using the freeware ImageJ (version 1.32j), available from the internet website: http://rsb.info.nih.gov/ij/.

\section{RESULTS}

\section{Mass Spectrometry Analysis of Native and Glycoxidized Albumin}

Oxidative modifications of proteins could occur in diabetes, which is one of the important pathological conditions associated with the early occurrence of vascular complications, together with functional alterations of albumin. In diabetes, albumin undergoes increased glycation and glycoxidation [14]. The glycation phenomenon corresponds to the non-enzymatic and non-oxidative covalent attachment of glucose molecule to protein [14]. Glycoxidation refers to the radical-mediated oxidation reaction of both free and proteinbound sugars [15]. Amadori rearrangement of the above glycated protein gives rise to deleterious, advanced glycoxidation (also termed advanced glycation) end products (AGEs) [16,17].

Modifications of commercial BSA when incubated with $0 \mathrm{mM}$ and $100 \mathrm{mM}$ of glucose were assessed by ESI/MS, which indicate the number of glucose molecule condensed on the protein. The most abundant component of native and glycoxidized albumin is shown in Fig. (1). Additional important characterizations of structural modifications in HSA and
BSA after incubating with varied concentration of glucose were previously performed by our group [18-20].

As expected, non-enzymatic glycosylation of BSA induces an increase in molecular weight for albumin incubated with $100 \mathrm{mM}$ of glucose, in comparison with native BSA. Here, the molecular mass represented by the most abundant component of non-modified BSA and glycoxidized albumin is $66438.47 \mathrm{Da}$ and $66759.98 \mathrm{Da}$, respectively. This increase of $321.51 \mathrm{Da}$ could correspond to the addition of two molecules of glucose unit to the glycoxidized albumin.

\section{Protein Expression in SW872 Cells after Incubation with Native or Glycoxidized Albumin}

Expression of up-regulated and/or down-regulated proteins in SW872 cell was analyzed on silver stained 2D gel after adipocyte incubation with native and glycoxidized albumin. The protein spots were excised from silver stained 2D gel, which separates the proteins by both charge and size. We selected 5 proteins spots that occupy the low molecular region. Fig. (2) represents the $2 \mathrm{D}$ gel in which the low molecular weight proteins expression levels are compared when SW872 cells were incubated with native or glycoxidized albumin. Proteins identified by mass spectrometry are listed according to the number on the silver stained gel as shown in Fig. (2).

In Table 1, proteins are identified using MALDI TOF/ TOF apparatus from the silver stained 2D gels. Identified proteins show higher expression level in $\mathrm{BSA}_{\mathrm{G} 100}$-treated cells. The proteins identified fall into few groups and in most instances a description of their crucial implication in adipocyte functioning can be discerned.

\section{DISCUSSION}

Diabetes and obesity constitute the major causative factor that can lead to the development of metabolic syndrome. Elevated concentration of glucose induces non-enzymatic glycosylation of albumin altering both the structure and the
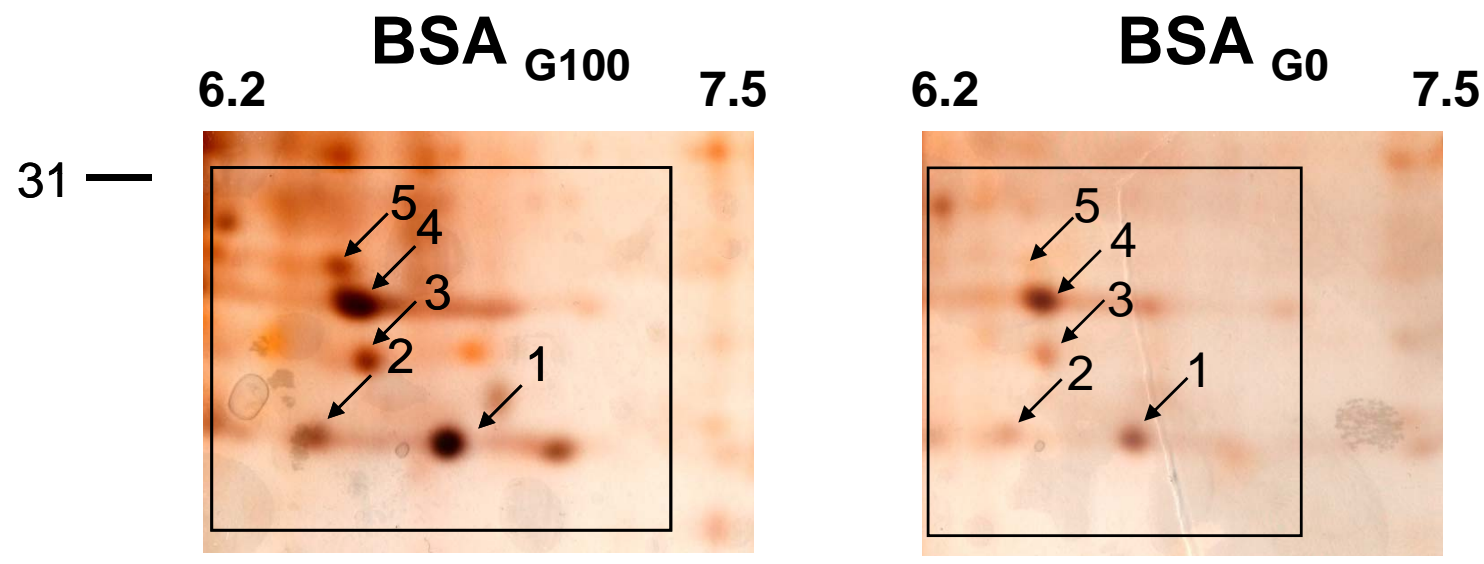

Fig. (2). Five low molecular weight proteins are higher expressed in AGEs-treated adipocytes.

SW872 cells were incubated for 16hrs in the presence of $20 \mu \mathrm{M}$ of $\mathrm{BSA}_{\mathrm{G} 100}$ or $\mathrm{BSA}_{\mathrm{G} 0}$. Cells were harvested, lysed and cell proteins were derivatized with DNPH (see Materials and methods). Samples (500 mg protein/gel) were separated on preparative 2D gels for Silver staining. Gel shown represents protein of less than $30 \mathrm{KDa}$ and $\mathrm{pI}$ 6.2-7.5 (left to right). The photos shown are representative of one experiment that was repeated with similar results three times. 
Table 1. Differentially Accumulated Proteins and their Identification by Mass Spectrometry were Listed According to the Numbering Shown in Fig. (2). Accession Numbers, Theoretical Molecular Weight (KDa) and Isoelectric Point, Number of Amino Acid Sequence Matched and Percentage Identification Score were Shown. Protein Identification was Performed at University of Angers and was Determined by Searching the Human Sub-Set of the Non-Redundant NCBI Database with Peptide Masses from MALDI Spectra

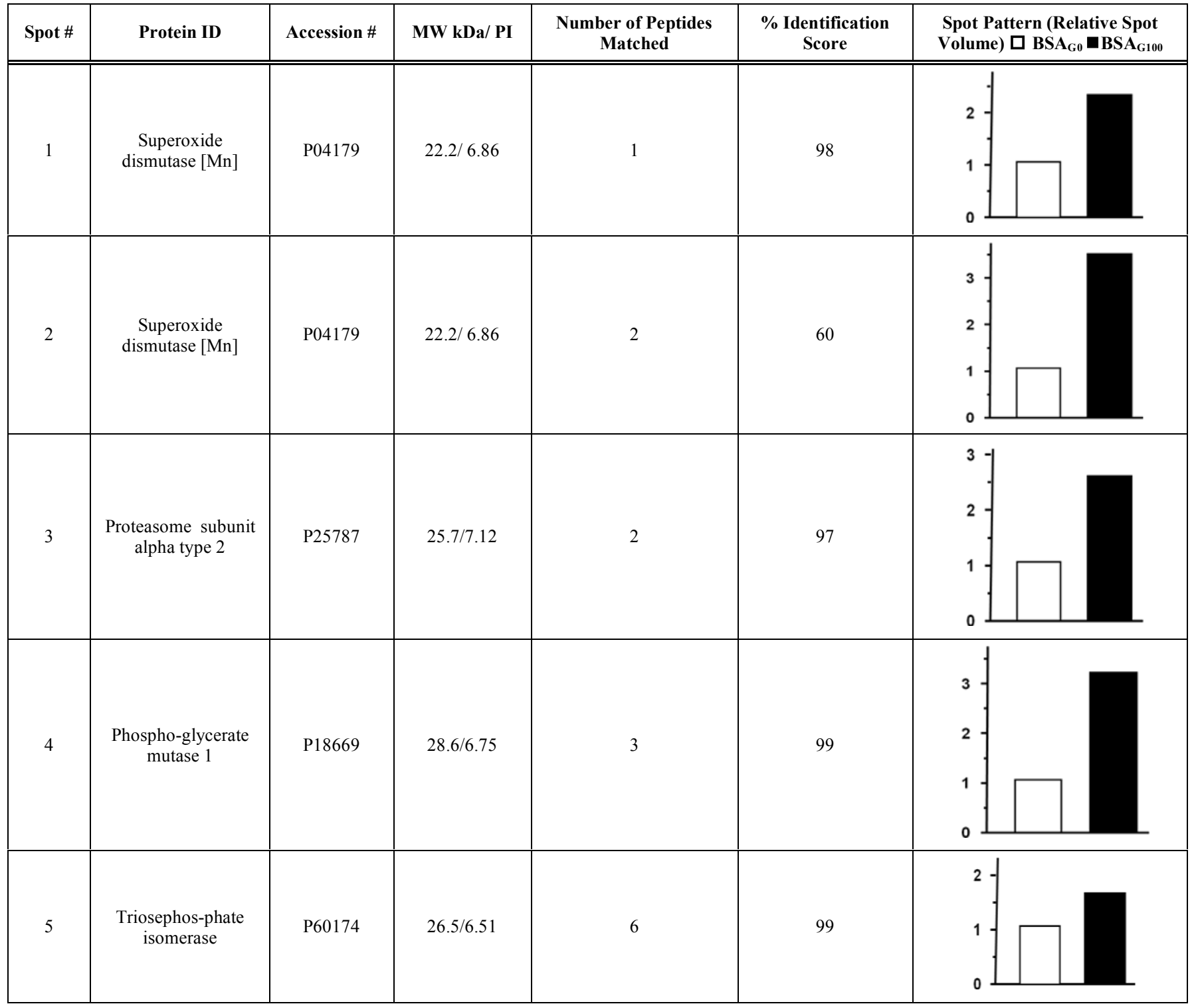

functions of this crucial plasmatic protein [21,22]. The current study was undertaken to identify dysregulated proteins in human adipocytes submitted to glycated albumin. SW872 cell line, which constitutes a good model for adipocytes, was used to analyze the expression level of proteins. In total, four low molecular proteins were selected for mass spectrometric identification because they were clearly over expressed in glycated BSA-treated adipocytes and distinctly positioned on two- dimensional gel. The proteins fall into few groups and in most instances a description of their crucial implication in SW872 functioning can be established.

Identified proteins belonged to different groups that include an antioxidant enzymatic system, degradation pathway and glycolysis pathway. Mitochondrial superoxide dismutase (MnSOD) is the major antioxidant protein found to be highly expressed in SW872 cells that were incubated with glycoxidized albumin compared to native albumin. MnSOD is manganese containing protein, which belongs to a large family of metalloproteins. The SOD protein family participates in scavenging superoxide radicals generated mainly by the electron transport system in mitochondria. High levels of MnSOD in SW872 cells incubated with glycoxidized albumin may be due to an enhanced synthesis of the enzyme in response to the oxidative stress. Yoo et al. have shown that glycated albumin induces superoxide generation in mesangial cells [23]. Very recently, enhanced ROS generation was evidenced in erythrocytes issued from $\mathrm{Cu} / \mathrm{Zn}$ SOD knock out mice [24]. A positive correlation was established between mitochondrial hydrogen peroxide generation, MnSOD activity and oxidative damages in lipids and proteins [25]. 
Similarly, there is a 3 fold increase in the expression levels of proteasomal subunit $\alpha 2$. Proteasome is a multi protein complex that is known to degrade altered protein. The 20S subunit of proteasome consists of two outer rings containing seven different $\alpha$-subunits $(\alpha 1-\alpha 7)$ and two middle central rings each is constituted by seven different $\beta$ subunits $(\beta 1-\beta 7)$. 20S subunit is involved in the degradation of oxidized proteins [26]. Reports from our group showed that enhanced oxidative stress and oxidative damages in AGEs-treated cells were associated with impairements in the proteasomal activities [7,20]. Increased expression level of proteasome in SW872 cells are consistent with very recent data from Schimdt et al who evidenced induction of heat shock proteins and the proteasome system by two different types of AGEs in Caco-2 cells [27].

Phosphoglycerate mutase 1 and triosephosphate isomerase proteins also appeared to accumulate more importantly in SW872 cells that were incubated with BSA $_{\mathrm{G} 100}$ than with $\mathrm{BSA}_{\mathrm{G} 0}$. These enzymes are closely involved in the glycolysis pathway, where the glucose is oxidized to produce energy. These enzymes are closely related to the insulin sensibility in adipocytes, which constitutes a emerging issue in the obesity-associated diabetes pathology [28].

This study warrants further investigation. Nonetheless, we propose that AGEs-mediated enhancement in the accumulation of these four proteins in adipocytes may be involved in the adipose tissue inflammation inherent to obesity-associated disorders.

\section{ACKNOWLEDGEMENTS}

The authors would like to acknowledge the Plateforme Technologique de Biotechnologie Moléculaire (Université d'Angers, France) for mass spectrometry analyses.

This work has been supported by the Ministère de l'Enseignement Supérieur et de la Recherche et de l'Outre Mer and the Université de La Réunion. NRS was supported by a fellowship from the Conseil Régional de La Réunion et de l'Union Européenne.

\section{ABBREVIATIONS}

\begin{tabular}{|c|c|c|}
\hline AGEs & $=$ & Advanced Glycated Endproducts \\
\hline BSA & $=$ & Bovine Serum Albumin \\
\hline $\mathrm{BSA}_{\mathrm{GX}}$ & $=$ & BSA incubated with $\mathrm{x} \mathrm{mM}$ of glucose \\
\hline $\mathrm{BSA}_{\mathrm{G} 0}$ & $=$ & BSA incubated without glucose \\
\hline OS & $=$ & Oxidative Stress \\
\hline PAGE & $=$ & Polyacrylamide Gel Electrophoresis \\
\hline ROS & $=$ & Reactive Oxygen Species \\
\hline
\end{tabular}

\section{REFERENCES}

[1] Droge W. Free radicals in the physiological control of cell function. Physiol Rev 2002; 82: 47-95.

[2] Wild S, Roglic G, Green A, Sicree R, King H. Global prevalence of diabetes: estimates for the year 2000 and projections for 2030 . Diabetes Care 2004; 27: 1047-53.

[3] Shoelson SE, Lee J, Goldfine AB. Inflammation and insulin resistance. J Clin Invest 2006; 116: 1793-801.
[4] Houstis N, Rosen ED, Lander ES. Reactive oxygen species have a causal role in multiple forms of insulin resistance. Nature 2006; 440: 944-8.

[5] Mayerson AB, Hundal RS, Dufour S, et al. The effects of rosiglitazone on insulin sensitivity, lipolysis, and hepatic and skeletal muscle triglyceride content in patients with type 2 diabetes. Diabetes 2002; 51: 797-802.

[6] Rahimi R, Nikfar S, Larijani B, Abdollahi M. A review on the role of antioxidants in the management of diabetes and its complications. Biomed Pharmacother 2005; 59: 365-73.

[7] Singh NR, Rondeau P, Hoareau L, Bourdon E. Identification of preferential protein targets for carbonylation in human mature adipocytes treated with native or glycated albumin. Free Radic Res 2007; 41: 1078-88.

[8] Wassef H, Bernier L, Davignon J, Cohn JS. Synthesis and secretion of apoC-I and apoE during maturation of human SW872 liposarcoma cells. J Nutr 2004; 134: 2935-41.

[9] Izem L, Morton RE. Possible role for intracellular cholesteryl ester transfer protein in adipocyte lipid metabolism and storage. J Biol Chem 2007; 282: 21856-65.

[10] Roche M, Tarnus E, Rondeau P, Bourdon E. Effects of nutritional antioxidants on AAPH- or AGEs-induced oxidative stress in human SW872 liposarcoma cells. Cell Biol Toxicol 2009; 25: 635-44.

[11] Carmel JF, Tarnus E, Cohn JS, Bourdon E, Davignon J, Bernier L. High expression of apolipoprotein E impairs lipid storage and promotes cell proliferation in human adipocytes. J Cell Biochem 2009; 106: 608-17.

[12] Tarnus E, Wassef H, Carmel JF, et al. Apolipoprotein E limits oxidative stress-induced cell dysfunctions in human adipocytes. FEBS Lett 2009; 583: 2042-8.

[13] Shevchenko AWM, Vorm O, Mann M. Mass spectrometric sequencing of proteins silver-stained polyacrylamide gels. Anal Chem 1996; 68: 850-8.

[14] Cohen MP. Intervention strategies to prevent pathogenetic effects of glycated albumin. Arch Biochem Biophys 2003; 419: 25-30.

[15] Pennathur S, Heinecke JW. Mechanisms for oxidative stress in diabetic cardiovascular disease. Antioxid Redox Signal 2007; 9: 955-69.

[16] Cohen MP, Shea E, Chen S, Shearman CW. Glycated albumin increases oxidative stress, activates NF-kappa B and extracellular signal-regulated kinase (ERK), and stimulates ERK-dependent transforming growth factor-beta 1 production in macrophage RAW cells. J Lab Clin Med 2003; 141: 242-9.

[17] Huebschmann AG, Regensteiner JG, Vlassara H, Reusch JE. Diabetes and advanced glycoxidation end products. Diabetes Care 2006; 29: 1420-32.

[18] Rondeau P, Armenta S, Caillens H, Chesne S, Bourdon E. Assessment of temperature effects on beta-aggregation of native and glycated albumin by FTIR spectroscopy and PAGE: relations between structural changes and antioxidant properties. Arch Biochem Biophys 2007; 460: 141-50.

[19] Chesne S, Rondeau P, Armenta S, Bourdon E. Effects of oxidative modifications induced by the glycation of bovine serum albumin on its structure and on cultured adipose cells. Biochimie 2006; 88 1467-77.

[20] Rondeau P, Singh NR, Caillens H, Tallet F, Bourdon E. Oxidative stresses induced by glycoxidized human or bovine serum albumin on human monocytes. Free Radic Biol Med 2008; 45: 799-812.

[21] Bourdon E, Loreau N, Blache D. Glucose and free radicals impair the antioxidant properties of serum albumin. FASEB J 1999; 13: 233-44.

[22] Roche M, Rondeau P, Singh NR, Tarnus E, Bourdon E. The antioxidant properties of serum albumin. FEBS Lett 2008; 582: 1783-7.

[23] Yoo BS, Regnier FE. Proteomic analysis of carbonylated proteins in two-dimensional gel electrophoresis using avidin-fluorescein affinity staining. Electrophoresis 2004; 25: 1334-41.

[24] Grzelak A, Kruszewski M, Macierzynska E, et al. The effects of superoxide dismutase knockout on the oxidative stress parameters and survival of mouse erythrocytes. Cell Mol Biol Lett 2009; 14: 23-34.

[25] Jolitha AB, Subramanyam MV, Asha DS. Modification by vitamin $\mathrm{E}$ and exercise of oxidative stress in regions of aging rat brain: studies on superoxide dismutase isoenzymes and protein oxidation status. Exp Gerontol 2006; 41: 753-63. 
[26] Shringarpure R, Grune T, Davies KJ. Protein oxidation and 20S proteasome-dependent proteolysis in mammalian cells. Cell Mol Life Sci 2001; 58: 1442-50.

[27] Schmid K, Haslbeck M, Buchner J, Somoza V. Induction of heat shock proteins and the proteasome system by casein-N epsilon- (carboxymethyl)lysine and $\mathrm{N}$ epsilon-(carboxymethyl)lysine in Caco-2 cells. Ann N Y Acad Sci 2008; 1126: 257-61.

[28] Scherer PE. Adipose tissue: from lipid storage compartment to endocrine organ. Diabetes 2006; 55: 1537-1545.

Received: June 24, 2009

(C) Singh et al.; Licensee Bentham Open.

This is an open access article licensed under the terms of the Creative Commons Attribution Non-Commercial License (http://creativecommons.org/licenses/by$\mathrm{nc} / 3.0 /$ ), which permits unrestricted, non-commercial use, distribution and reproduction in any medium, provided the work is properly cited. 